\title{
Clinical efficacy of a short course of systemic steroids in nasal polyposis*
}

\author{
Virat Kirtsreesakul, Krongthong Wongsritrang, Suwalee Ruttanaphol
}

Department of Otolaryngology, Faculty of Medicine, Prince of Songkla University, Thailand

SUMMARY Background: Although oral steroids are widely used for the treatment of nasal polyposis, a subset of patients shows an unfavorable therapeutic outcome. The aim of this study was to evaluate the efficacy of a short course of oral prednisolone in nasal polyposis and to evaluate which, if any, clinical variables can predict treatment outcome in these patients.

Methodology/Principal: Using a 3:2 randomization ratio, 63 patients with nasal polyposis received $50 \mathrm{mg}$ of prednisolone and 46 patients received placebo daily for 14 days. Clinical response was evaluated by total nasal symptoms score (TNSS), peak expiratory flow index (PEFI) and total nasal polyps score (TNPS). Potential predictor variables were assessed by clinical history, nasal endoscopy, allergy skin test and sinus radiography.

Results: The prednisolone-treated group showed significantly greater improvements in all nasal symptoms, nasal flow and polyp size than the placebo-treated group. In the prednisolone-treated group, patients with grade 3 polyps and positive nasal endoscopy showed significantly less improvement in TNSS, PEFI and TNPS than patients with grades 1-2 size and with negative nasal endoscopy.

Conclusions: A short course of oral steroids showed good clinical efficacy in the treatment of nasal polyposis, however, polyps size grade 3 andlor positive nasal endoscopy predispose to a poorer treatment outcome.

Key words: corticosteroids, efficacy, nasal polyposis, predictor, steroid insensitivity

\section{INTRODUCTION}

Nasal polyposis is a chronic inflammatory disease of the sinonasal mucosa, which can have a major effect on quality of life. Because of its uncertain etiology, treatment options differ, mainly in the choice between medical and surgical management. Corticosteroids are the only medical therapy to have a proven effect on the symptoms and signs of nasal polyps and can be used topically or systemically. Topical steroids are the mainstay treatment and can be used in long term therapy (1); however, up to one-half of patients do not respond to the steroids and need surgical treatment ${ }^{(2,3)}$. Systemic steroids, although less well studied, usually affect all types of symptoms and pathologies ${ }^{(4)}$. Systemic steroids are only used for short duration treatment, due to concern about possible side effects with long-term use ${ }^{(5)}$. They are most often used at the beginning of treatment in severe cases or after failure of topical steroids therapy.

Even with the improved treatment options provided by systemic steroids, a certain number of nasal polyps patients have a poor response to treatment and up to $31.5 \%$ need surgical treatment ${ }^{(6,7)}$. Nasal polyposis is a multifactorial disease, in which interaction of different predisposing factors and comorbid disorders may influence treatment outcome. Potential contributing factors include allergy, sinusitis, asthma, aspirin intolerance and size of polyps. Whether nasal polyposis with some of these factors is less sensitive to steroid therapy than those without is still a controversial issue. Many recent studies have found that nasal polyposis patients with one or more of these factors have a poor response to steroid therapy and a higher recurrence rate after surgery ${ }^{(8-22)}$. However, these results may be criticized because most of these studies were retrospective in design, and to date there has been no direct comparative study to evaluate the direct effects of these factors on the therapeutic response of corticosteroids in nasal polyposis. Knowledge of the effects of these possibly predicative variables would be useful in treatment planning and identifying patients most likely to benefit from early surgical intervention in nasal polyposis. 
To address the issues discussed above, oral prednisolone, a potent and widely used systemic anti-inflammatory medication, was used to explore the medical efficacy and examine potential clinical predictors of steroid non-responsive nasal polyposis. We designed a randomized double blind placebo controlled trial to carefully evaluate the effects of a short course of oral prednisolone on nasal symptoms, nasal peak flow and polyps size. We further examined any association between the possible predictive variables, e.g. demographic data, history of aspirin sensitivity, asthma, allergy skin test and sinusitis, on the therapeutic response to the oral steroids.

\section{MATERIALS AND METHODS}

The study was conducted on 109 patients with nasal polyposis at the Allergy and Rhinology Clinic, Department of Otolaryngology, Faculty of Medicine, Songklanagarind Hospital, Prince of Songkla University, Songkhla, Thailand, between May 1, 2007 and April 30, 2010. The protocol was approved by the Ethics Committee of the Faculty of Medicine, Prince of Songkla University. All patients gave signed, informed consent before being recruited into the study.

\section{Inclusion and Exclusion Criteria}

Patients with benign bilateral nasal polyps diagnosed clinically and confirmed by nasal endoscopy were included in the study. Patients were excluded if they had symptoms or physical signs suggestive of renal disease, hepatic disease, diabetes mellitus, cataract, glaucoma, cardiovascular disease, unstable asthma, cystic fibrosis, mucociliary disorders, immuno-compromise, severe septal deviation or acute infection within 2 months. Patients who used nasal, inhaled or systemic steroids within 2 months, an antihistamine within 2-7 days and/or a decongestant within 2 days, or had previous sinonasal surgery were also excluded from the study.

\section{Data collection}

The medical history of each subject, including age, sex, nasal symptoms, concomitant diseases and current medications, was recorded. The diagnosis of aspirin intolerance was made based on a clear-cut history of asthma attacks precipitated by nonsteroidal anti-inflammatory drugs (NSAIDs). Asthma was noted if the patient had a history of recurrent wheezing, dyspnea, chest tightness, or cough (particularly at night), and a normal chest $\mathrm{x}$-ray. The criteria for diagnosis of rhinosinusitis were rhinitis symptoms (nasal blockage, rhinorrhea/ postnasal drip, facial pain/ pressure and hyposmia), positive nasal endoscopy (mucoid or mucopurulent discharge from the middle meatus or superior meatus) and/or positive sinus radiography ( $\geq 1$ abnormal finding on a plain film of the paranasal sinus (Caldwell and Waters view), e.g. haziness, opacity, air-fluid level or mucosal thickening more than $4 \mathrm{~mm}$ ).

An allergy skin prick test was performed with 18 common aeroallergens (Bermuda grass, Johnson grass, acacia, careless weed, Alternaria species, Aspergillus mix, Candida albi- cans, Penicillium mix, fusarium, cat pelt, dog epithelium, mixed feathers, kapok, Dermatophagoides pteronyssinus, Dermatophagoides farinae, American cockroach, pyrethrum and Cladosporium sphaerospermum; all from Allertech Co, Ltd, Bangkok, Thailand). Histamine phosphate $2.75 \mathrm{mg} / \mathrm{ml}$ was used as a positive control and glycerin saline as a negative control. Skin wheal diameters were determined at 20 minutes using the mean of the longest diameter and the perpendicular mid point diameter. A positive reaction was defined as a skin wheal diameter of at least $3 \mathrm{~mm}$ greater than the negative control skin wheal.

Patients were randomly assigned at a $3: 2$ ratio to receive $50 \mathrm{mg}$ of prednisolone or placebo, respectively. All medications were taken daily for 14 days, and all patients were blinded to their treatment regimen. The dosage and duration of prednisolone were selected as the maximum safe dose that could be given to adults without inducing lasting adrenal suppression and allowing drug cessation without tapering ${ }^{(5,23)}$. They were told that the use of other medications for rhinitis or allergy was not allowed during their participation in this study. Study personnel were not informed of a patient's treatment regimen until all assessments were completed. All patients were instructed to return their remaining drug at the 14-day post-trial follow-up visit. The patient's compliance with his or her study medication was defined as the percentage of the prescribed doses taken.

\section{Clinical assessment}

Evaluations of the patients' symptoms were performed at pretreatment and at the end of the trial, 14 days after the first treatment was given, based on scores assessing blocked nose, runny nose, sneezing, nasal itching, hyposmia, postnasal drip, cough and sinonasal pain. The severity of each individual symptom was assessed with a 7-point Likert scale, with score $0=$ no symptoms, score $1-2$ = mild symptoms (steady symptoms but easily tolerable), score $3-4=$ moderate symptoms (symptoms hard to tolerate, might interfere with activities of daily living, sleep, or both), and score 5 - $6=$ severe symptoms (symptoms so bad that the person could not function virtually all the time). The sum of the individual nasal symptom scores gave the total nasal symptoms score (TNSS). At the end of the study period, each patient rated their global symptom control (GSC) on a 100-point visual analog scale, ranging from $0=$ no control over symptoms to $100=$ total control over symptoms.

Nasal patency was assessed at each visit by using the nasal and oral peak expiratory flows index (PEFI). A Mini-Wright peak flowmeter (Clement Clarke International Ltd, London, UK) connected to an anesthetic facemask covering both nose and the mouth, instead of a mouthpiece, was used for nasal PEF measurements. The patients were instructed to keep their lips tightly closed while performing the maximal total expiratory effort through the nose after a maximal inspiration. Peak flow rate was read from a cursor in liters per minute. The best of three readings with a variation of less than $10 \%$ was considered 
the true peak flow, which was then recorded as the result. The PEFI was calculated as the nasal PEF divided by the oral PEF to compensate for changes in lung function.

Nasal polyps size was assessed by nasal endoscopy and scored on a 0 - 3 scale as follows: score 0 : no polyps, score 1: mild polyposis (small polyps, extending downward from the upper nasal cavity but not below the upper edge of the inferior turbinate, causing only slight obstruction), score 2: moderate polyposis (medium sized polyps, extending downward from the upper nasal cavity and reaching between the upper and lower edges of the inferior turbinate, causing troublesome obstruction), score 3: severe polyposis (large sized polyps, extending downward from the upper nasal cavity and reaching below the lower edge of the inferior turbinate, causing total or almost total obstruction). The total nasal polyps score (TNPS) was calculated as the sum of the polyps scores for each nostril.

\section{Statistical analysis}

Demographic data comparisons between the groups were made using the chi-square test. The Komolgorov-Smirnov test was used to test continuous variables for any deviations from normality. In comparisons of TNSS, PEFI, TNPS and GSC within and between the groups, the paired or unpaired T-test was used for parametric data and the Wilcoxon signed-rank test or the Mann-Whitney U test for nonparametric data. In the prednisolone-treated group, the differences of percentage improvements in TNSS, GSC, TNPS and PEFI between nasal polyps patients with positive and negative prognostic factors were compared with the Mann-Whitney $U$ test and unpaired T-test, respectively. Variables statistically different between the positive and negative prognostic factor groups in the univariate analysis were included in a multiple linear regression analysis with stepwise entry of variables; the dependent variables were percentage changes in TNSS, PEFI, TNPS and GSC to identify independent predictive factors of poor response to treatment with oral prednisolone. In all tests of significance, two-tailed alternatives were used. A p value of less than 0.05 was considered statistically significant.

\section{RESULTS}

\section{Study Population}

Between May 1, 2007, and April 30, 2010, 112 patients were enrolled in the study. Sixty-five and 47 patients were randomized into the prednisolone and placebo-treated groups, respectively. Two patients in the prednisolone-treated group and 1 patient in the placebo-treated group did not attend their follow-up visit because of logistical problems (Figure 1), and were removed from the analyses. The baseline characteristics of the prednisolone and placebo-treated groups including nasal symptom scores are presented in Table 1 . There were no statistically significant differences in patient characteristics and nasal symptoms between the two groups. Compliance with the study medication was essentially the same in each group $(96.6 \%$, and $96.9 \%$ for the prednisolone and placebo groups, respectively).
Nasal symptoms, PEF index, polyps size and global symptom control

Following the treatment period, the assessed scores of blocked nose, runny nose, sneezing, nasal itching, hyposmia, postnasal drip, cough and sinonasal pain, PEFI, polyps size and GSC significantly improved within the prednisolone-treated group, while although nasal symptom scores in the placebo-treated group also showed significant improvements, there were no significant improvements in either objective outcome, PEFI and polyps size (Figure 2). In comparisons between the treatment groups, the prednisolone-treated group showed significant differences in all TNSS, PEFI, TNPS and GSC scores compared with the placebo-treated group (all $\mathrm{p}<0.001$ ) (Figure 2).

\section{Adverse effects}

GI disturbances and dyspepsia were noted more frequently in the subjects being treated with prednisolone (Table 2). Other side effects were infrequent and were not significantly different between the groups. No patient reported significant adverse symptoms during the days immediately after cessation of the prednisolone.

\section{Potentially predictive factors for treatment outcome}

To determine which clinical parameters might predict the therapeutic response to oral prednisolone, different hypothesized predictive variables were analysed. Univariate analysis comparing these factors with treatment outcomes, indicated by percentage changes in TNSS, PEFI, TNPS and GSC after treatment were performed to identify the factors to be included in the subsequent multivariate analysis. Among these factors, univariate analysis showed that patients with polyps grade 3 , positive nasal endoscopy and positive sinus radiography showed less improvement in some or all treatment outcomes than patients with polyps grades 1 and 2, negative nasal endoscopy and negative sinus radiography (Table 3 ).

In a multiple linear regression analysis, using percentage changes in TNSS, PEFI, polyps size and GSC scores as the dependent variables, we entered three independent predictive variables: polyps grade, nasal endoscopy and sinus radiography. In this analysis, polyps grade and nasal endoscopy were significant predictors of treatment outcome, as the coefficient indicated that increasing polyps size or positive nasal endoscopy predicted poorer therapeutic response. Sinus radiography did not show any impact on treatment outcome in multiple linear regression analysis (Table 4).

\section{DISCUSSION}

Although oral steroids are most often used in high doses for a short duration at the beginning of treatment in severe cases or after failure of topical steroids therapy, their clinical efficacy has not been well studied. In this study, we assessed the efficacy of oral prednisolone in nasal polyposis in a placebocontrolled, randomized, double-blind study. The outcome measures included each patient's subjective assessment of nasal 


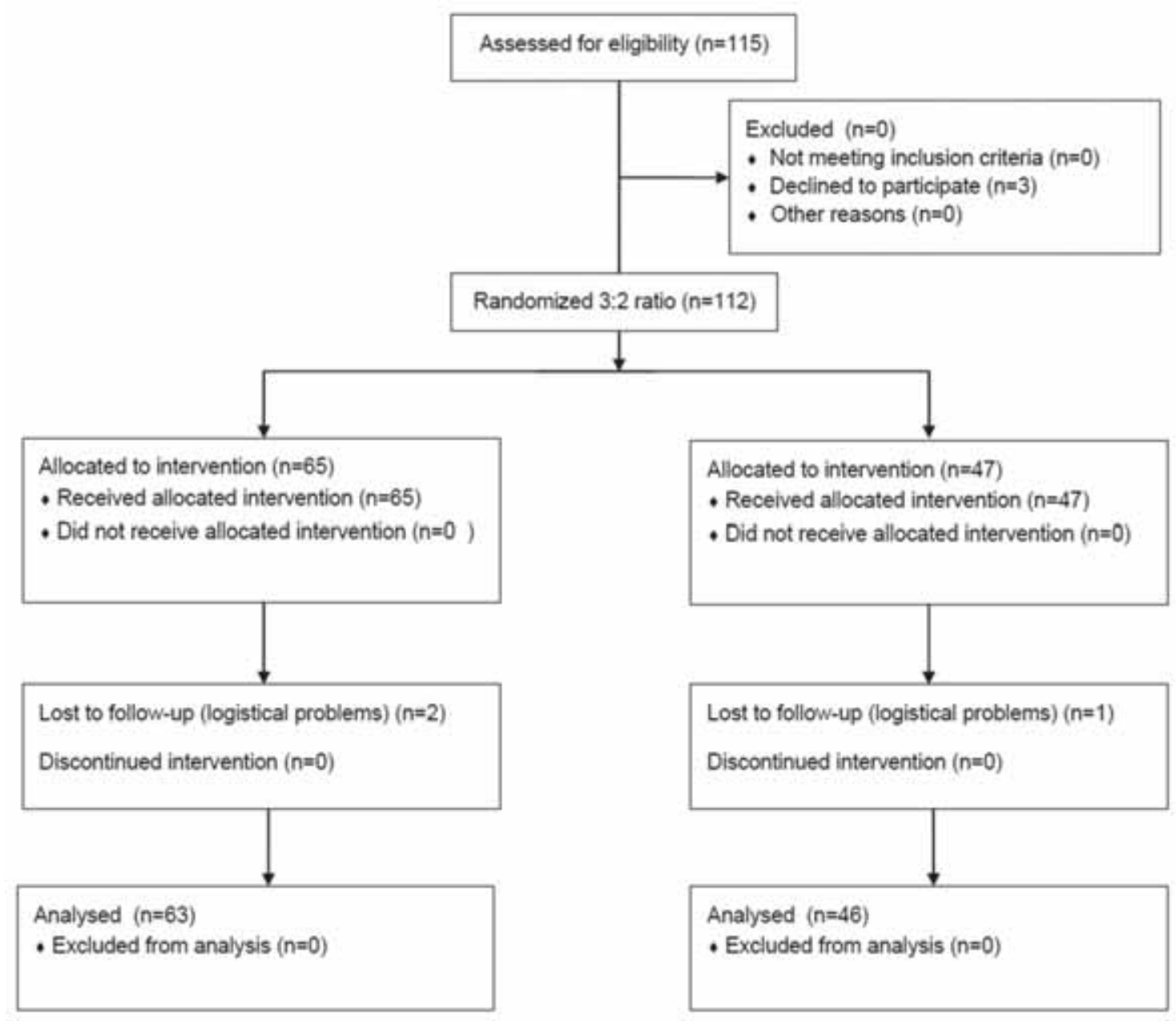

Figure 1. Patient flow diagram.

symptoms and global symptom control, and objective measures including nasal patency and polyps size. In the subjective outcomes, there was a statistically significant improvement of all nasal symptom scores and global symptom control in both the placebo and prednisolone-treated groups of patients, but the level of improvement was significantly greater in the prednisolone-treated group. This suggests that the improvements in subjective symptoms could have been, in part, caused by a placebo effect. In objective outcome assessments, nasal patency was assessed by using peak expiratory flow indexes (PEFIs) and the size of polyps was assessed through nasal endoscopy. Although subjective nasal symptom improvements were noted in both groups, objective improvements as assessed through PEFI and nasal endoscopy were found only in the prednisolone-treated group. Because of a lack of a correlation between the severity of nasal symptoms and the extent of nasal polyposis, we used both subjective and objective assessments to evaluate the changes in the disease severity after treatment. The objective outcomes confirmed the treatment efficacy of oral steroids in nasal polyposis.
Although oral steroids used in the study showed good therapeutic effects in the treatment of nasal polyposis, a certain number of patients showed only limited clinical improvement. Nasal polyposis is a multifactorial disease, in which the interaction of varying predisposing factors and comorbid disorders could have varying degrees of impact on the treatment outcome. To date, to our knowledge, there are no reports in the literature correlating clinical improvements with systemic steroid treatment in nasal polyposis to pretreatment clinical factors. Our study found that nasal polyps patients with polyps size grade 3 or positive nasal endoscopy had worse therapeutic responses than nasal polyps patients with polyps size grades 1-2 or negative nasal endoscopy. Nasal polyposis with positive sinus radiography showed less improvement in some treatment outcomes than with negative sinus radiography in univariate analysis; however, when these variables were all considered together using multiple regressions, nasal polyps size and positive nasal endoscopy, but not positive sinus radiography, confirmed their negative impacts. 
Table 1. Baseline characteristics, comparing prednisolone and placebo-treated groups.

\begin{tabular}{|c|c|c|c|}
\hline Characteristic & $\begin{array}{l}\text { Prednisolone-treated group } \\
(\mathrm{n}=63)\end{array}$ & $\begin{array}{l}\text { Placebo-treated group } \\
(\mathrm{n}=46)\end{array}$ & $\mathrm{p}$ value \\
\hline $\begin{array}{l}\text { Age }(\text { Yrs }) \\
\text { - Mean } \\
\text { - Range }\end{array}$ & $\begin{array}{c}44.7 \\
18-65\end{array}$ & $\begin{array}{c}46.6 \\
18-65\end{array}$ & 0.435 \\
\hline Sex ratio $(\mathrm{M} / \mathrm{F})$ & $42: 21$ & $28: 18$ & 0.551 \\
\hline $\begin{array}{l}\text { Duration of symptoms (Yrs) } \\
\text { - Mean } \\
\text { - Range }\end{array}$ & $\begin{array}{c}7.7 \\
0.5-30\end{array}$ & $\begin{array}{c}7.5 \\
0.5-20\end{array}$ & 0.859 \\
\hline $\begin{array}{l}\text { Concomitant disease } \\
\text { - Aspirin sensitivity } \\
\text { - Asthma } \\
\text { - Positive allergy skin test } \\
\text { - Positive nasal endoscopy } \\
\text { - Positive sinus radiography }\end{array}$ & $\begin{array}{l}4 \\
17 \\
34 \\
25 \\
48 \\
\end{array}$ & $\begin{array}{c}4 \\
13 \\
25 \\
17 \\
39 \\
\end{array}$ & $\begin{array}{l}0.457 \\
0.526 \\
0.562 \\
0.843 \\
0.195 \\
\end{array}$ \\
\hline $\begin{array}{l}\text { Score at first visit }(\text { Mean } \pm \text { SD) } \\
\text { - Blocked nose } \\
\text { - Rhinorrhea } \\
\text { - Sneezing } \\
\text { - Nasal itching } \\
\text { - Hyposmia } \\
\text { - Postnasal drip } \\
\text { - Cough } \\
\text { - Sinonasal pain } \\
\text { - Total nasal polyps score } \\
\text { - PEF index }\end{array}$ & $\begin{array}{l}4.06 \pm 1.46 \\
3.06 \pm 1.87 \\
2.68 \pm 1.79 \\
1.86 \pm 1.86 \\
3.51 \pm 2.24 \\
2.59 \pm 1.77 \\
1.51 \pm 1.52 \\
1.69 \pm 1.84 \\
3.37 \pm 1.37 \\
0.35 \pm 0.11\end{array}$ & $\begin{array}{l}3.63 \pm 1.44 \\
3.30 \pm 1.77 \\
2.59 \pm 1.34 \\
2.39 \pm 1.88 \\
3.41 \pm 2.47 \\
3.00 \pm 1.87 \\
1.54 \pm 1.77 \\
2.28 \pm 1.60 \\
3.09 \pm 1.05 \\
0.38 \pm 0.14\end{array}$ & $\begin{array}{l}0.132 \\
0.551 \\
0.992 \\
0.086 \\
0.972 \\
0.255 \\
0.919 \\
0.054 \\
0.423 \\
0.247\end{array}$ \\
\hline
\end{tabular}

Table 2. Adverse events.

\begin{tabular}{lcc}
\hline Adverse event & Prednisolone-treated group & Placebo-treated group \\
\hline Gastrointestinal disturbance & 10 & 1 \\
Dyspepsia & 4 & 1 \\
Increased appetite & 1 & 0 \\
Fatigue & 1 & 0 \\
Acne & 1 & 0 \\
Headache & 1 & 1 \\
Insomnia & 1 & 0 \\
Sore throat & 1 & 1 \\
\hline
\end{tabular}

In clinical practice, large nasal polyposis generally has a poor therapeutic response to nasal steroids because obstruction caused by the polyps mass prevents the nasal steroids from having its full effect. Surprisingly, in our study, although there was a clinical improvement in large nasal polyps with systemic steroids, patients with nasal polyps grade 3 also had significantly less therapeutic improvement compared to the smaller sizes, grades 1 and 2. Background cell resistance to corticosteroids in large nasal polyposis with more severe inflammation might be a major cause of this therapeutic failure ${ }^{(8)}$. Increased expression of $\mathrm{GRb}$ in nasal polyposis has been proposed as one of the potential mechanisms explaining steroid resistance (13). The expression of GRb has been correlated with increased infiltration of inflammatory cells and inversely correlated with steroid responsiveness ${ }^{(9,12)}$.

Nasal polyposis is associated with chronic inflammation of the mucosal lining of the nasal cavities and sinuses. One possibility is that serious obstruction caused by multiple nasal polyps reduces the clearance of bacteria, leading to amplified infection as the infected sinus cavities become reservoirs for pathogenic bacteria causing recurrent or persistence infection. Interactions between infectious stimulus and nasal polyposis could cause poor treatment outcomes ${ }^{(8,13)}$. We used sinus radiography and nasal endoscopy to diagnose rhinosinusitis. Nasal polyposis with positive nasal endoscopy, but not positive sinus radiography, showed a worse therapeutic response to systemic steroids compared with nasal polyposis with negative nasal endoscopy. Abnormal sinus radiography could be caused from both noninfectious inflammation and/or infection. Noninfectious sinus inflammation would be improved with the strong anti-inflammatory effect of systemic steroids. Positive nasal endoscopy is more likely to represent true sinus infection and be associated with poor treatment outcome.

Allergy and asthma are frequently associated with nasal polyposis and may influence treatment outcomes. Allergic rhinitis, in particular perennial allergic rhinitis that causes long-lasting inflammation of the nasal mucosa, may be a relevant factor in the pathogenesis of nasal polyposis ${ }^{(14,15)}$. Earlier studies have 

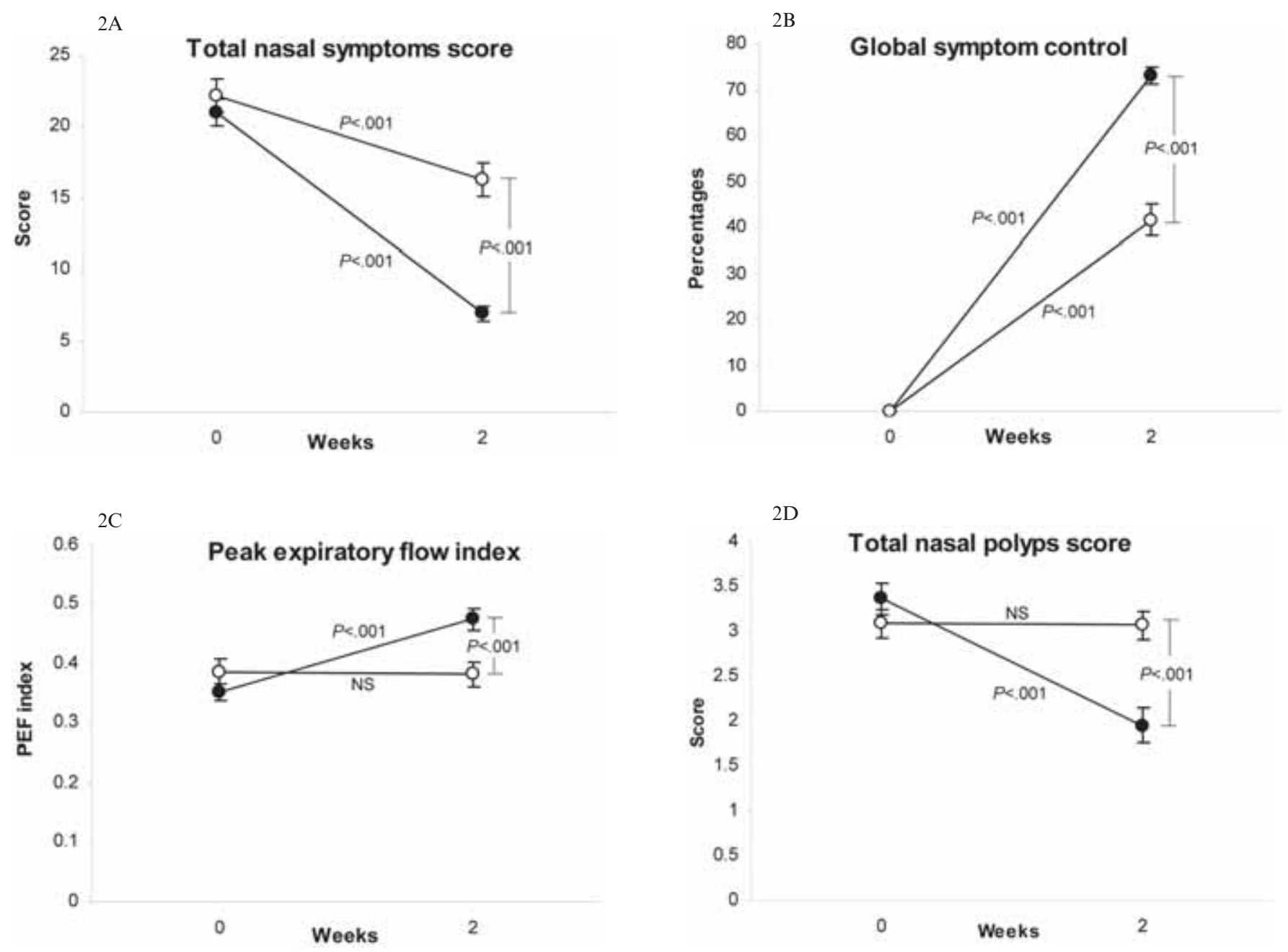

Figure 2. Scores at baseline and 2 weeks after treatment of patients with nasal polyposis with $50 \mathrm{mg}$ of prednisolone (closed circle) or placebo (open circle) daily. A: total nasal symptoms score, B: global symptom control, C: peak expiratory flow index, D: total nasal polyps score. Data are shown as mean \pm SEM. P values within and between the groups of PEFI and TPNS were calculated using Student $t$ test, and of TNSS and GSC were calculated using Wilcoxon test, and are shown in the figures.

found that nasal polyposis with a positive skin test had poor therapeutic response to topical steroids ${ }^{(16)}$, and also a greater recurrence rate after surgery ${ }^{(17,18)}$. Other studies have found that nasal polyposis with concomitant asthma had less symptom improvements, worse postoperative endoscopic findings and a higher recurrence rate after sinus surgery ${ }^{(19,20)}$. In the current study, with oral prednisolone treatment, a history of asthma and/or positive skin test was not related to a negative impact on therapeutic improvements. Systemic steroids with a potent anti-inflammatory action might be highly effective in the control of asthma and allergic inflammatory diseases associated with nasal polyposis. Nasal polyposis with aspirin sensitivity has been associated with a particularly persistent and treatment-resistant form of disease. In some studies, aspirin sensitivity has been found to have adversely affected sinus surgery outcomes, be associated with a higher proclivity to disease recurrence and more frequently require revision surgery ${ }^{21,22)}$. Because only 4 patients in our study had aspirin sensitivity, the numbers were too small to perform statistical comparisons with non-sensitive patients.

Our findings suggest that large polyps size and/or positive nasal endoscopy can be considered a major risk factor for steroid insensitivity in patients with nasal polyposis and surgical treatment might be considered earlier in the management of such patients.

We note some limitations of this study. First, although conventional sinus radiography can be used as a screening method for sinus inflammation and these findings, including haziness/ opacification, air fluid level and mucosal thickening, have been correlated with rhinosinusitis ${ }^{(24,25)}$, false positive and false negative results have also been reported ${ }^{(26)}$. Abnormal sinus radiography should be interpreted in the context of clinical examination, nasal endoscopy or both. A CT scan is the imaging modality of choice to confirm the anatomy and extent of pathology. The major advantage of CT over plain films is improved visualization of the ethmoid complex, frontal recess 
Table 3. Univariate analysis comparing post-treatment percentage changes in TNSS, PEFI and polyps size reduction and GSC with potentially predictive independent variables.

\begin{tabular}{lccc}
\hline $\begin{array}{l}\text { Potentially predictive vari- } \\
\text { able }\end{array}$ & $\begin{array}{c}\text { \% TNSS Improvement } \\
(\mathrm{p} \text { value })\end{array}$ & $\begin{array}{c}\text { \% PEFI Improvement } \\
(\mathrm{p} \text { value })\end{array}$ & $\begin{array}{c}\text { \% Polyps size reduction } \\
(\mathrm{p} \text { value })\end{array}$ \\
\hline Sex & 0.265 & 0.103 & 0.183 \\
Age & 0.998 & 0.334 & 0.543 \\
Duration & 0.465 & 0.265 & 0.670 \\
Asthma & 0.500 & 0.319 & 0.182 \\
Skin test & 0.276 & 0.815 & 0.714 \\
Nasal endoscopy & 0.030 & 0.001 & 0.780 \\
Polyps size & $<0.001$ & 0.001 & 0.009 \\
Sinus radiography & 0.055 & 0.036 & 0.777 \\
\hline
\end{tabular}

Table 4. Multivariate linear regression analysis of potentially predictive variables with percentage improvements in TNSS, PEFI and polyps size reduction and GSC after treatment.

\begin{tabular}{|c|c|c|c|c|c|c|c|c|c|c|c|c|}
\hline \multirow{2}{*}{$\begin{array}{l}\text { Potentially predic- } \\
\text { tive Variable }\end{array}$} & \multicolumn{3}{|c|}{$\%$ TNSS Improvement } & \multicolumn{3}{|c|}{$\%$ PEFI Improvement } & \multicolumn{3}{|c|}{$\%$ Polyps size reduction } & \multicolumn{3}{|c|}{ GSC } \\
\hline & $\beta$ & $\mathrm{t}$ & $\mathrm{p}$ value & $\beta$ & $\mathrm{t}$ & $\mathrm{p}$ value & $\beta$ & $\mathrm{t}$ & $\mathrm{p}$ value & $\beta$ & $\mathrm{t}$ & p value \\
\hline Nasal endoscopy & -0.193 & -1.359 & 0.180 & 0.574 & 4.698 & $<0.001$ & -0.323 & -2.418 & 0.019 & -0.116 & -0.799 & 0.428 \\
\hline Polyps size & -0.281 & -2.171 & 0.034 & 0.296 & 2.669 & 0.010 & -0.318 & -2.223 & 0.030 & -0.418 & -2.698 & 0.009 \\
\hline Sinus radiography & -0.119 & -0.757 & 0.452 & -0.230 & -1.709 & 0.093 & -0.009 & -0.062 & 0.951 & -0.059 & -0.372 & 0.712 \\
\hline
\end{tabular}

and soft tissue. However, in some situations the availability of CT imaging is limited by cost and considerations of radiation dosage ${ }^{(25)}$. Also our findings represent an examination of the

short-term effects of oral steroids in patients with nasal polyps, and longer clinical trials with topical steroids are necessary to examine the long-term therapeutic effects and reliable clinical predictors of this intervention.

\section{CONCLUSION}

The main findings of the current study were 1) a short course of oral steroids showed good clinical efficacy in the treatment of nasal polyposis, 2) polyps grade 3 and/or nasal polyps with positive nasal endoscopy had a significant negative impact on therapeutic outcome, and 3) clinical improvements with oral steroid treatment were not influenced by allergy, asthma or positive sinus radiography.

\section{ACKNOWLEDGEMENTS}

The study was supported by the Faculty of Medicine, Prince of Songkla University, Thailand.

\section{AUTHOR'S CONTRIBUTIONS}

VK: study concept and design; data collection, analysis, and interpretation; writer; KW: study design, data collection; SR: data collection.

\section{CONFLICT OF INTEREST}

There are no conflicts of interest for this work.

\section{REFERENCES}

1. Joe SA, Thambi R, Huang J. A systematic review of the use of intranasal steroids in the treatment of chronic rhinosinusitis. Otolaryngol Head Neck Surg. 2008; 139: 340-347.

2. Badia L, and Lund V. Topical corticosteroids in nasal polyposis. Drugs. 2001; 61: 573-578.

3. Dalziel K, Stein K, Round A, et al. Systematic review of endoscopic sinus surgery for nasal polyps. Health Technol Assess. 2003; 7: 1-159.

4. Patiar S, Reece P. Oral steroids for nasal polyps. Cochrane Database Syst Rev. 2007; 24: 1-13.

5. Hissaria P, Smith W, Wormald PJ, et al. Short course of systemic corticosteroids in sinonasal polyposis: a double-blind, randomized, placebo-controlled trial with evaluation of outcome measures. J Allergy Clin Immunol. 2006; 118: 128-133.

6. Nores JM, Avan P, Bonfils P. Medical management of nasal polyposis: a study in a series of 152 consecutive patients. Rhinology. 2003; 41: 97-102.

7. Bonfils $\mathrm{P}$, Norès $\mathrm{JM}$, Halimi $\mathrm{P}, \mathrm{A}$ van $\mathrm{P}$. Corticosteroid treatment in nasal polyposis with a three-year follow-up period. Laryngoscope. 2003; 113: 683-687.

8. Kim HY, Dhong HJ, Chung SK, Chung YJ, Min JY. Prognostic factors of pediatric endoscopic sinus surgery. Int J Pediatr Otorhinolaryngol. 2005; 69: 1535-1539.

9. Hamilos DL, Leung DY, Muro S, et al. GR beta expression in nasal polyp inflammatory cells and its relationship to the antiinflammatory effects of intranasal fluticasone. J Allergy Clin Immunol. 2001; 108: 59-68.

10. Mjaanes CM, Whelan GJ, Szefler SJ. Corticosteroid therapy in asthma: predictors of responsiveness. Clin Chest Med. 2006; 27: 119-132.

11. Ito K, Chung KF, Adcock IM. Update on glucocorticoid action and resistance. J Allergy Clin Immunol. 2006; 117: 522-543.

12. Adcock IM, Barnes PJ. Molecular mechanisms of corticosteroid resistance. Chest. 2008; 134: 394-401.

13. Slavin RG. Nasal polyps and sinusitis. JAMA. 1997; 278: 18491854.

14. Asero R, and Bottazzi G. Nasal polyposis: a study of its association with airborne allergen hypersensitivity. Ann Allergy Asthma 
Immunol. 2001; 86: 283-285.

15. Bunnag C, Pacharee P, Vipulakom P, Siriyananda C. A study of allergic factors in nasal polyp patients. Ann Allergy. 1983; 50: 126-132.

16. Kirtsreesakul V. Role of allergy in the therapeutic response of nasal polyps. Asian Pac J Allergy Immunol. 2002; 20: 141-146.

17. Settipane GA. Nasal polyps and immunoglobulin E (IgE). Allergy Asthma Proc. 1996; 17: 269-273.

18. Dursun E, Korkmaz H, Eryilmaz A, et al. Clinical predictors of long-term success after endoscopic sinus surgery. Otolaryngol Head Neck Surg. 2003; 129: 526-531.

19. Bonfils P, Avan P. Non-specific bronchial hyperresponsiveness is a risk factor for steroid insensitivity in nasal polyposis. Acta Otolaryngol. 2004; 124: 290-296.

20. Albu S, Tomescu E, Mexca Z, Nistor S, Necula S, Cozlean A. Recurrence rates in endonasal surgery for polyposis. Acta Otorhinolaryngol Belg. 2004; 58: 79-86.

21. Batra PS, Kern RC, Tripathi A, et al. Outcome analysis of ESS in patients with nasal polyps and asthma. Laryngoscope. 2003; 113: 1703-1706.

22. Amar YG, Frenkiel S, Sobol SE. Outcome analysis of ESS for chronic sinusitis in patients having Samter's Triad. J Otolaryngol. 2000; 29: 7-12

23. Verbeek PR, Geerts WH. Nontapering versus tapering prednisone in acute exacerbations of asthma: a pilot trial. J Emerg Med. 1995;
13: 715-719.

24. Meltzer EO, Hamilos DL, Hadley JA, et al. Rhinosinusitis: developing guidance for clinical trials. J Allergy Clin Immunol. 2006; 118 (5 Suppl): S17-61.

25. Rosenfeld RM, Andes D, Bhattacharyya N, et al. Clinical practice guideline: adult sinusitis.Otolaryngol Head Neck Surg. 2007; 137(3 Suppl): S1-31.

26. Fokkens W, Lund V, Mullol J, et al. European position paper on rhinosinusitis and nasal polyps 2007. Rhinol 2007; 20 (Suppl): $1-136$.

Virat Kirtsreesakul, MD

Division of Allergy and Rhinology

Department of Otolaryngology, Faculty of Medicine

Prince of Songkla University

Hat Yai, Songkhla, 90110

Thailand

Tel: +66-74-429-620

Fax: +66-74-429-620

E-mail: kvirat2002@yahoo.com

University of Pennsylvania Department of OtorhinolaryngologyHead and Neck Surgery and Department of Neurosurgery Present:

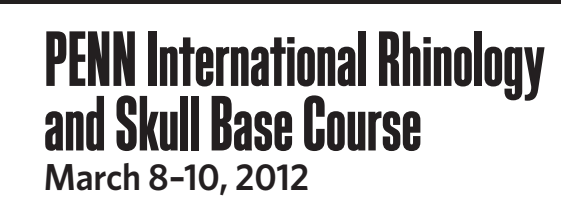

PENW Rhinoplasty Course
March 10-11, 2012

The Westin Philadelphia

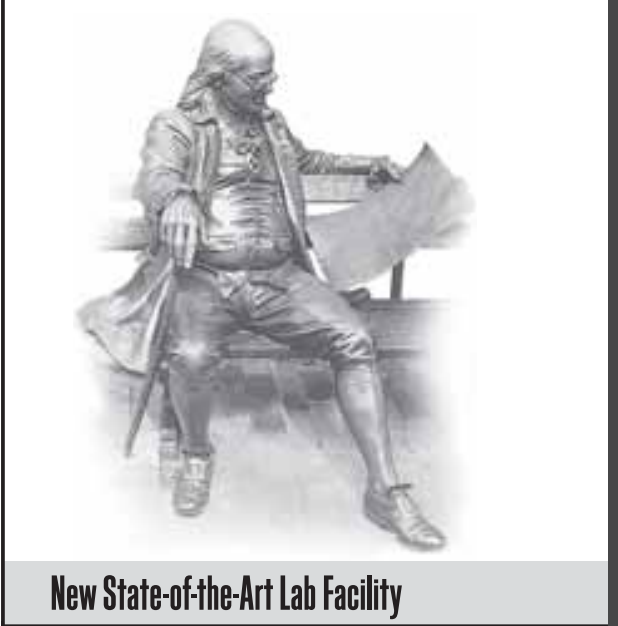

For more information:

PHONE: 215-349-5382 - FAX: 215-662-4515

EMAlL: cathy.lafferty@uphs.upenn.edu

WEBSITE: http://www.uphs.upenn.edu/pennorl

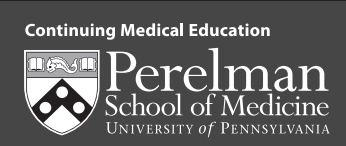

PENN International Rhinology

and Skull Base Course

EXECUTIVE DIRECTOR (ORL-HNS CME)

James N. Palmer, MD

COURSE CO-DIRECTORS

Bert W. O'Malley, Jr., MD

David W. Kennedy MD

Noam A. Cohen, MD, PhD

Noam A. Cohen, MD,
Nithin Adappa, MD

Nithin Adappa, MD
M. Sean Grady, MD

John Y.K. Lee, MD

PENN DISTINGUISHED

SKULL BASE PROFESSORSHIP

Paolo Cappabianca, MD

Piero Nicolai, MD

GUEST FACULTY

Rakesh Chandra, MD

Alexander G. Chiu, MD

Costas G. Hadjipanayis, MD, PhD

John Jane, Jr., MD

G. Michael Lemole, Jr., MD

Rodney J. Schlosser, MD

PENN Rhinoplasty Course

COURSE DIRECTOR

Oren Friedman, MD

COURSE CO-DIRECTORS

Ara A. Chalian, MD

Daniel G. Becker, MD

GUEST FACULTY

Paul Carniol, MD

Stephen A. Goldstein, MD

Grant Hamilton, MD

Grant Hamilton, MD
Eugene B. Kern, MD

Eugene B. Kern,
Ira D. Papel, MD

Tom D. Wang, MD

The Perelman School of Medicine at the University of Pennsylvania is accredited by the Accreditation Council for Continuing Medical Education (ACCME) to provide continuing medical education for physicians. These activities are approved for AMA PRA Category 1 Credits" 